\title{
O MOVIMENTO CRIATIVO EM A NOÇÃO DE POEMA, DE NUNO JÚDICE
}

Chimena Barros da GAMA (UNESP/Araraquara) ${ }^{1}$

RESUMO: O texto apresenta uma abordagem à obra A Noção de Poema (1972), de Nuno Júdice. Através da análise de algumas composições, verifica-se como o poeta evidencia constantemente o processo pelo qual o poema passa para ser finalizado e ressalta-se a imagem obsessiva do movimento, frequentemente vinculada à agitação do ato criador.

PALAVRAS-CHAVE: Nuno Júdice, A Noção de Poema, criação, metapoesia.

ABSTRACT: The text introduces an approach to Nuno's Júdice book A Noção de Poema (1972). Through the analyses of some compositions it is ascertain how the poet constantly makes clear the process in which the poem went through to be done and it is underscore the obsessive image of movement frequently related to the exciting of the creation act.

KEYWORDS: Nuno Júdice, A noção do poema, creation, metapoetry.

Nuno Júdice é um dos maiores nomes da poesia portuguesa contemporânea. Aos sessenta anos, o autor, nascido em 1949, apresenta uma vasta obra poética, cujas características mais marcantes são a visão crítica acerca da própria literatura, o diálogo com as outras artes, além da reflexão (filosófica) na economia dos poemas, que é traço de sua poesia desde o primeiro livro, do início dos anos 70 , e reaparece em suas outras obras, que formam um conjunto de mais de duas dezenas de coletâneas poéticas. Como os autores herdeiros da aguda consciência artística romântica, Júdice é poeta crítico, crítico poeta, criador, contemplador e questionador ao mesmo tempo, o que é intensificado por sua obra como ensaísta e crítico, e por sua carreira como professor Universitário. É criador de uma lírica que faz pensar, instiga o leitor, e mereceu importantes prêmios literários, como o prêmio Pablo Neruda e o Grande Prêmio de Poesia APE.

Suas obras iniciais são da década de setenta, seguindo, assim, cronologicamente, a época de uma poesia portuguesa bastante voltada para a experimentação da linguagem 
e repleta de poemas mais concisos, em que se buscava a palavra exata, em uma exatidão experimental. Mas em A Noção de Poema, vê-se um poeta inclinado para outro estilo, com versos e estrofes longos, espraiamento discursivo e linguagem bastante fragmentária, como se essa unidade, essa exatidão experimental requerida pela poesia dos anos 60, se estilhaçasse em sua poesia. É assim em seu livro de estreia, em Crítica Domésticados Paralelepípedos(1973) e em $O$ Mecanismo Romântico da Fragmentação (1975), só para citar algumas de suas obras dos anos 70. Já nas recolhas da década de 80 e 90, Júdice dá continuidade a esse estilo, mas surgem, aqui e ali, alguns sonetos e poemas mais concisos, com uma forma que pode ser chamada de mais tradicional.

Para além do aspecto formal, sua poesia apresenta, ainda, uma série de referências literárias, artísticas, filosóficas, históricas e geográficas, que pedem do seu leitor uma erudição tão grande quanto a sua. E tudo isso desde a Noção de Poema, livro que analisaremos mais de perto. Trata-se de uma obra importante, não só no âmbito da carreira poética de seu criador, mas no curso da história da poesia portuguesa (e ocidental), na qual está inserida como sua revisora. É nesse sentido que a estudiosa Ida Alves afirma que

[...] sua obra nos possibilita discutir de forma imediata uma teorização da escrita e da leitura na poesia portuguesa mais recente, uma vez que, desde o seu primeiro livro, A Noção de Poema (1972), preocupa-se sobremaneira com a realização do poema e a compreensão do "ato poético", questionando o sujeito lírico e sua existência no texto e no mundo (ALVES, 2006, sem página, itálico da autora).

Com tantas publicações do poeta posteriores à coletânea de 1972, ela ainda interessa pelo que de vivo há em sua tessitura poética, e quando dizemos "vivo", queremos dizer aquilo que ainda move tanto o poeta como, provavelmente, seus leitores. Vivo, portanto, porque pulsa nos poemas da obra, e, como se verá, movimentase dentro dela, criando um jogo de espelhos entre o ato criativo e a própria arte.

A Noção de Poema coloca seu leitor constantemente em movimento: ele acompanha, passo a passo, o processo de criação do poeta. A "noção" de "poema" é então colocada em xeque: já não se trata de algo pré-estabelecido, mas de uma ideia de 
texto poético que se vai firmando nas composições do livro, ao longo da revelação do movimento de criação do próprio poema, e que está fundamentalmente vinculada ao processo criativo.

É sob esse prisma que o autor antecipa a coletânea ao seu leitor, reproduzindo afirmação de Rui Diniz em epígrafe:

A arte, diz-se, põe hoje problemas da sua teoria no próprio acto da sua invenção. Põe-se a si mesma em causa no interior de si mesma; procura, no gesto com que se cria, definir-se, postular-se, explicar-se de forma mais próxima de si [...] (apud JUDICE, 1991, p.09).

O primeiro texto da obra, "Apogeu da gramática", é todo formado através desse movimento, desse "gesto" anunciado nas palavras de Diniz, e sintetiza procedimentos e temas marcantes da recolha de poemas2:

(1) Como iniciar o canto, a homenagem às cidades imprevisíveis do continente

(2) fulgurativo? Como ordenar a substância nomeativa das ampolas avinhadas,

[ o xadrez

(3) terrestre de uma legifera sabedoria? Respondereis: a esplêndida antiguidade

(4) do desvio, a íntima conformidade de um estilo memorativo, de uma poética

(5) exilante, de um verso solsticial. Não obstante, as gramáticas oficiantes

(6) de uma memória ocidental limitaram o meu génio. [...]

(JUDICE, 1991, p.11)

Nos dois primeiros versos, revela-se a questão inicial para qualquer poeta, ao desejar nova criação: "como" fazê-la? O poema já anuncia, pois, sua problemática primeira - o modo de sua realização - e também "expõe" o que seria o tema tratado: "as cidades imprevisíveis". Lembra a poesia, comum na modernidade literária, de busca do procedimento artístico, de "luta com a palavra" poética, eternizada nos versos do poeta brasileiro Carlos Drummond de Andrade3, a ironia romântica de desvelamento da aguda consciência artística e autocrítica do escritor. Porém, os versos que se seguem ao longo de toda a composição subvertem a questão do que parecia ser um tema. Porque as "cidades" são "imprevisíveis", imprevisível é também o jogo que o poema apresenta, e já não são as "cidades", mas toda a agitação tensa entre o poeta e a criação que vai 
surgindo, como um jato, nos versos. Desta forma, o leitor entra no universo da própria criação como ato, “[...] pelo desnudamento do próprio processo criativo de desconstrução [...]" palavras da crítica portuguesa Ana Paula Arnaut (2002, p.52), que, embora estejam se referindo a narrativas pós-modernistas, cabem perfeitamente nos poemas do livro de Júdice.

A adjetivação é abundante, e muitas vezes insólita e rebuscada (com encadeamento de longos adjetivos), tanto nos seis versos apresentados, como também em todo o poema, conferindo-lhe certo barroquismo. Mas é herança barroca inerente ao estilo e, ao mesmo tempo, questionada através dele, pois as próprias adjetivações acumuladas problematizam a presença desta e de outras heranças literárias no momento da escrita. O que poderia ser solução - a assimilação de todo um patrimônio artístico passado - é, na verdade, conflituoso, e vem à tona sua refuta, a questão da inovação, da busca do próprio estilo4. Enfim, os adjetivos concentram sentidos importantes no poema, que se volta sobre si mesmo, da gênese ao acabamento, da inspiração ao encontro com o canto finalizado. O poeta, assim, assimila um traço de uma poética passada, mas, paradoxalmente, está questionando, até meados da composição, sua formação literária e a assimilação desta.

Com efeito, trata-se, no princípio, da recuperação de alguma noção de escrita poética que vem à mente do artista no momento do encontro com a página em branco: "a esplêndidaantiguidade do desvio", "a íntima conformidade de um estilo memorativo, de uma poética/exilante [...]" são expressões que retomam algumas "noções" de poema, identificadas com tradição, mas uma tradição de "desvio" - de uma linguagem desviante e diferenciada -; com a ideia de conformação (também recuperada no 29o. verso, em que se lê "longe das métricasconformadas") - e talvez de adequação, bem como de conformismo com aquilo que já é visto como "poema". Noções identificadas, também, com a questão da permanência da arte, de sua dimensão imperecível e memorialista; e, enfim, com a própria figura da poesia como "exilante" deixando o poeta no exílio, fora do mundo.

Tais seriam as soluções para o poema (note-se o "Respondereis", no terceiro verso), o "como" deveria ou poderia ser criado. Recuperando mais um traço poético do 
passado, o poeta utiliza a expressão romântica "génio", e revela que o próprio movimento criativo vê, nessa herança, algo que o tolhe, com suas canônicas "gramáticas oficiantes de uma memória ocidental" - note-se que, mais uma vez, através da adjetivação abundante, o poema traz a "noção" cristalizada, mencionando a autoridade gramatical, e o peso da "memória ocidental". Assim, em acréscimo às outras expressões apontadas ("esplêndida antiguidade", "conformidade de um estilo memorativo"), o poeta vai criando uma imagem de poéticas anteriores que podem surgir no momento da busca da escrita. Algumas outras expressões adjetivadas como "voz milenar", "condenação polar do sonho" e "engenharia meia-noitecida das manipulações narrativas" carregam mais ainda o texto com a noção de poesia legisladora e engenhosa calcada nas "gramáticas oficiantes" - "elas", que aparecem no texto três vezes:

(6)

(7) com a interioridade vocativa da voz milenar,a prática interdita do presságio; (8) elas me expuseram à condenação polar do sonho, elas enfim, estimulantes (9) tatuadoras de uma álgebra animal, me forneceram a ocasião única do

[ Espelho, (10) a visão do duplo longínquo, a engenharia meia-noitecida das manipulações (11) narrativas, o esculpir óptico das frases basílicas do litígio!

(JUDICE, 1991, p.11, negrito nosso)

No momento primitivo do poema, aquele em que toda a formação literária do poeta vem à tona, seu sujeito apresenta-se como passivo ("me impuseram"; "me expuseram"; "meforneceram"), sinalizando, deste modo, a quase que impossibilidade de criar algo de seu, diante do passado de leituras e aprendizagem (passado manifesto nos tempos verbais). E ele não está livre desse passado literário "tatuador" e capaz de fornecer-lhe "a ocasião única do espelho", que pode ser lida como a necessidade e a capacidade de emular poéticas precedentes. No entanto, o movimento do poema expõe a tentativa de libertação, e o cume desse ato de recuperação da formação e de leituras passadas apresenta-se nas “frases basílicas do litígio!”, síntese de todo esse passado recuperado (basílicas: relicário, palácio real, igreja principal; litígio: relacionado ao judicial), questionando-o como autoridade. 
O poema refuta tais noções prévias de si próprio, embora revele também que elas estiveram cravadas no poeta (talvez em sua formação como literato, em sua apreciação da poesia), e que despontam no momento inicial de uma criação.

Na contínua mobilidade do processo criativo, os versos seguintes apontam um caminho de rompimento com as poéticas anteriormente refutadas. Há algo de novo, ainda não começado, no $12^{\circ}$. verso, "Iniciarei...", não obstante se confirme, ao longo da leitura, que este "início" não é tão novo assim.

Agora, já não são a "elas", as "gramáticas", que os versos se opõem, mas aos "indolentes espigadores de inconsumibilidade" - ressalte-se o substantivo, relacionado a espigar, desenvolver, germinar, como se "espigadores" deixassem sua semente -, que são alvo de refuta do 120 . ao 22o. verso. O "canto" ganha, então, nova perspectiva, a do rompimento, a do pedido de algo novo, implícita nas expressões "canto requisidor" e "solicitação aventureira da exigência":

(12) Iniciarei pois um canto requisidor ao alcance do século. Palavra,

(13) solicitação aventureira da exigência, desordem curva do erro! Nunca

(14) os indolentes espigadores de inconsumibilidade ousaram a alma. Soubessem eles

(15) as promessas do Múltiplo, nunca os seus dedos aflorariam o olhar lógico

(16) do ritual, a veracidade instante da pálpebra! tivessem florescido

(17) as suas imprecisas vigílias, nunca eles reverenciariam a estranheza frontal

(18) do sofisma! pudesse o navegador de lábios murmurar o regresso, nunca

(19) o verão fecundaria o resoluto voo dos seus gestos! Eles são testemunhas fronteiras de

(20) um hábito de divindade, construtores perceptivos

(21) do avesso, intérpretes da abjuração

(22) do estigma! Eles celebram a tensão prepositiva do número - doentes

(23) de lucidez.

(JUDICE, 1991, p.11-12)

A reiteração do modo subjuntivo (“soubessem..."; “tivessem..."; "pudesse...") sugere a impossibilidade de, no passado, vislumbrar-se o que o sujeito do poema (poeta) consegue ver, em posição privilegiada, e aponta a variabilidade de "noções de poema" perdida por essa imposição, regulação e desejo de permanência dos "indolentes espigadores" ou das "gramáticas oficiantes". Eles representam, ainda, toda uma tradição 
clássica da poesia metrificada ("Eles celebram a tensão prepositiva dos números"), retórica, "vigilante", aqueles para quem o "poema" deveria ser eterno, imperecível e não expor suas "costuras".

"Eis contra quem proponho o contágio temporal do poema", canta o poeta no 24o. verso. Vislumbra-se aqui a inserção do objeto poético no tempo e no mundo, questionada sua carga de eternidade e universalidade absoluta. Porém, nesse momento de encontro com a noção de poema desejada, para que, finalmente, o poema surja (mas ele já surgiu, e eis o seu principal paradoxo, que é ir surgindo, enquanto o poeta aparentemente o pensa e o constrói), o verbo utilizado não é mais “iniciar”. Recorde-se que a composição começa com as palavras "Como iniciar...", em ato de autorreferência, ou seja, o poema começa questionando como começar. Ao mesmo tempo, o verbo “iniciar” é também sinal da busca de uma nova prática poética, ainda não iniciada, o que se evidencia no verso já visto: "Iniciarei pois um canto requisidor [...]". Contudo, como a arte "põe-se a si mesma em causa no interior de si mesma", conforme afirma Diniz, a própria questão da novidade é também colocada em causa: entre o 24o. e o 32o. verso, concentra-se o sentido de ruptura, mas não de novidade: “eu reinicio a prática...", diz o 28o. verso:

(24) Eis contra quem proponho o contágio temporal do poema. Atento

(25) à autoridade divina, esperando o refluxo atlântico dos ventos litorais,

(26) habitante da reconstrução do cisma, eu me concedo uma incómoda herança,

(27) o silêncio sangrento da ruptura; eu reinvento uma civilização

(28) segregativa, expurgada da fumigação diurna da vulgaridade; eu reinicio (29) a prática de uma aristocracia tumultuosa, longe das métricas conformadas (30) dos cultores de celebração - elogiando a intenção paranoica

(31) do poema, o desespero enfático da solidão, a cor

(32) espaçosa da genealogia...

(JUDICE, 1991, p.12)

As palavras em negrito reforçam o sentido de corte com o passado, e os três vocábulos utilizados com o prefixo "re" - "reconstrução", "reinvento" e "reinicio" -, revelam que não se trata de um rompimento inédito: consciente de que se encontra no campo da "tradição da ruptura", a que se refere o poeta e ensaísta mexicano Octávio Paz 
(1995, p.331-345), o poema não obtém em suas questões algo de singularmente diferente. Porque o rompimento com a poesia tradicional, com as "métricas conformadas", com as "gramáticas oficiantes", já se deu, e é constante na história literária. Por isso mesmo, a ideia de ruptura surge, em "Apogeu da Gramática", como "incómoda herança". Como todo adjetivo está super significado neste poema, vislumbra-se que o gesto de ruptura é também problemático, visto que é "incómodo" - e "como" começar algo novo, após tantas mudanças?

Em qualquer poeta, o penoso momento em que se encontra entre as leituras canônicas e a busca do novo ou de um modo próprio de cantar (imprevisível, como "as cidades") pode demorar a ser superado. Em Nuno Júdice, ele é matéria para o próprio poema. Tanto que se nota, nesta criação, e em outras do mesmo livro, a "intenção paranóica do poema" e a "cor espaçosa da genealogia...", versos referentes ao próprio canto, que revelam "as intenções" do poema e suas relações de apropriação/refutação do passado literário. Tendo a palavra "genealogia" um significado também vinculado ao estudo de ascendência de linhagens nobres, é possível, ainda, que todo aquele passado refutado/recuperado nesta primeira composição esteja inserido nela; note-se que a "genealogia" é "espaçosa" - da mesma forma que ela ocupa muito espaço ao longo da composição.

Eis, que, enfim, o poeta revela de forma mais ostensiva aquilo que o próprio poema ia revelando por meio de seus procedimentos e sua estrutura movimentada: o "Poema!" e as diretrizes dadas a ele por seu criador:

(33) Poema! - suspende o impulso ártico da nomeação! Tu bordarás a descrição (34) púrpura de uma flor libertadora. Os teus lábios fechar-se-ão à obliqüidade (35) porosa da prosódia. Ordenarás a extensa nomenclatura da imagem. Não (36) te detenhas no estuário reversível da metáfora! Cumpre o espírito emissário (37) das hierarquias outonais! Regressam já as aves indicativas do idioma. Elas

(38) dizem: "está próxima."

(39) Ei-la - a cidade.

(JUDICE, 1991, p.12-13) 
Há alteração no ritmo e na sintaxe desses versos, quase um manifesto literário, em que o poeta exclama e usa imperativos, apontando caminhos para a composição. Finalmente, ele consegue ordenar aquilo que entende por poema, libertando-se das amarras do passado. Sua "noção de poema" começa, pois, a ser esboçada, partindo de postulados como a interrupção da nomeação e a adesão à descrição - e o rompimento com determinada "noção de poema" em que este, de alcance ontológico, "nomeia" o objeto renovando seu sentido -; porém, "descrição púrpura" e dada pelo "bordado", ou seja, inovadora, artística. Outrossim, nota-se o afastamento das regras de prosódia; a ordenação das palavras na "imagem"; e, finalmente, a ultrapassagem do momento metafórico, no qual, para existir, esse "Poema" não deve se paralisar. Cumpre ressaltar que toda essa estrofe configura a superação do conflito entre o passado/formação literária do poeta e seu anseio por algo novo.

É significativa a enumeração (caótica) dos itens para que o eu poético consiga criar sua noção de poema (e só assim consiga chegar ao "como"): ela não é canônica, também não totalmente inovadora, mas intenta ultrapassar os imperativos da linguagem poética (a imagem, a metáfora, a prosódia), em busca de si mesma. É assim que, enfim, o esforço para criar o poema se acaba, e é possível ver ao menos uma "cidade", no último verso. Imprevisível, sem dúvidas, sobretudo porque a composição acaba no momento em que ela, "a cidade", uma das cidades anunciadas no início da composição, surge. Em contrapartida, de modo bastante denso, o próprio poema é completamente movimentado e caótico como uma cidade.

Ele é inteiro um movimento, uma busca e um processo, não somente nas sínteses semânticas contidas nas expressões supra-adjetivadas (chamemo-las assim), mas também na estrutura composicional. Os versos longos, como que configurando um contínuo ilimitado, mostram, como em um "jato", as implicações inerentes à invenção poemática e o percurso do poeta; o uso das linhas inferiores para prolongar os versos provoca um vai e vem no olhar do leitor, como se o poema transitasse, ou sobrevoasse um longo espaço aéreo, rapidamente, até localizar, enfim, "a cidade”. A presença das "aves indicativas do idioma" pode reforçar essa imagem de sobrevôo, bem como cria a imagem da inspiração, da fúria com que o poeta cria, rondando, sobrevoando, o papel em branco. 
Ademais, o texto configura o diálogo com várias poéticas: barroca, clássica, romântica, até surrealista - veja-se a enumeração caótica e a semelhança com a escrita automática (embora seja apenas um caso de semelhança) -; e apresenta a tensão entre a recuperação e a ruptura com o passado. Coloca-o em evidência, mas, ao mesmo tempo, desautoriza-o.

Cumpre ressaltar a importância do passado artístico em várias criações do livro: a formação do autor, as leituras de antigos e modernos, o diálogo com eles, informa muitos de seus poemas, cujo canto abrange mitologias, expressões e imagens simbolistas, posturas românticas, expõe palavras como barroco e neoclássico, faz referências à Mallarmé e Hölderlin etc. O livro, assim, vai se tornando um mosaico de poéticas, ao mesmo tempo em que estas, juntas, formam a noção de poema de seu autor, noção esta sempre presente em seu horizonte, pois, conforme já adiantamos, Júdice não deixa de recorrer à intertextualidade ao longo de toda a sua obra, como lembra, também, Alves (2006, sem página), ao abordar toda sua poesia.

A primeira composição é um exemplar de como o poeta insere seu leitor na problemática e nos movimentos do processo criativo. Aliás, a ideia do "movimento" fora antecipada pelo artista, no texto prefaciador da primeira edição da obra, em que se lê: "[...] Tudo se pode reduzir a fórmulas simples de movimento." (1972, p.11), e que termina com uma síntese acerca de todos os poemas da obra, e, parece, do que é esse "movimento": "E pude assumir as violentas consequências do poema, a vontade desordenada, o espírito inquieto da criação" (1972, p.13). Do mesmo modo, Y. K. Centeno, na recensão crítica da obra para a revista Colóquio Letras, afirma, com relação ao poeta: "[...] tudo lhe serve de pretexto, de ponto de partida, nos poemas que põe em movimento." (1972, p.81, negrito nosso).

Se o termo "noção" tem como sinônimos as palavras "conhecimento" e "ideia", é fato que ele é desconstruído nesse livro de Júdice. O que se conhece, em geral, como "poema" nem sempre é exatamente o que o autor coloca nas páginas do livro. Pegue-se, por exemplo, a composição “A praia de Tourgeville” (inspirada pela obra do pintor impressionista Eugène Boudin), cuja estrutura inicial é em versos que vão tornando-se 
cada vez mais longos e meditativos, à maneira de um ensaio sobre arte, sobretudo neste trecho final:

$[\ldots]$

$\mathrm{Na}$ origem, a ausência quase de desenho. A sóbria oposição de umas a outras manchas, o litoral sem o difícil contorno dos rochedos, formas extensas e assimétricas - isto e, uma arte intimista que, recusando o barroco, assume a inteira claridade do seu próprio desenho, recusa o desígnio e a estética, interessa-se, com sábio misticismo, pela melancolia e pela tristeza, pela fúria tranqüila da composição, pelo estudo da alma e da paisagem, pela descoberta da sombra e da cor, pelo movimento da realidade, pela pura alusão.

(JUDICE, 1991, p.19)

Note-se que essas palavras conservam os mesmos sentidos implícitos no poema anteriormente visto, "Apogeu da Gramática": trata-se de obsessão idêntica pelo processo criativo que rompe com as formas habituais e com o passado - "ausência quase de desenho"; "recusando o barroco"; "recusa o desígnio e a estética" -, e de suas etapas, técnicas e perspectivas - "estudo da alma e da paisagem"; "descoberta da sombra e da cor"; "movimento da realidade"; "pura alusão".

Ademais, todo o poema "borda a descrição púrpura", ou seja, assim como apontou na sua noção de poema da primeira composição do livro, a significação em "A praia de Tourgeville" se dá por meio de descrições do quadro; porém, descrições "bordadas", pois não diretas ou imparciais, mas misturadas à reflexão e às impressões do sujeito lírico: "Neste óleo de tela, assinado em baixo, à esquerda,/ parece-me ver o excessivo amor com que, alguns dias, olho/ o horizonte inteiro e as nuvens, como se chovesse [...]" (JÚDICE, 1991, p.18). Cumpre, assim, outra estratégia "meta-artística", posto que as impressões descritas no poema são retiradas de uma obra impressionista.

É preciso ressaltar que o "movimento"5 anunciado no texto prefaciador, notado por Centeno, e há pouco analisado detidamente em "Apogeu da Gramática” enquanto agitação criativa, continua sendo explorado em "A praia de Tourgeville", em três camadas: ele é sugerido pela pintura de Boudin - "a espuma embranquecida das ondas que rebentam” (JÚDICE, 1991, p.18, negrito nosso); “a leve impressão do vôo das 
gaivotas" (JÚDICE, 1991, p.18, negrito nosso) -; é imaginado no próprio ato do pintor, que procura "o movimento natural da paisagem" (JÚDICE, 1991, p.18, negrito nosso) e que "fixou, [...] com mobilidade sugerida, a praia/ de Tourgeville [...]" (JÚDICE, 1991, p.19, negrito nosso); e está, enfim, na reflexão do poeta acerca da obra, tentando recuperar o movimento criativo do pintor, nos versos transcritos acima. É reforçado, também, pela epígrafe da composição, uma espécie de apresentação enciclopédica do artista (não sabemos se o autor retirou-a ou não de algum catálogo ou livro sobre arte): "BOUDIN, Eugène - Pintor do ar livre, do céu e do mar, foi o primeiro a procurar fixar os aspectos daconstante transformação da natureza" (JÚDICE, 1991, p.18, negrito nosso).

Eis um poema cuja noção só pode ser pensada depois de lido. Poesia? Ensaio sobre arte? Meditação? Ele corresponde (como vários outros do livro) a traços marcantes na poética pós-modernista, vários deles elencados por Arnaut no capítulo "Para uma poética do post-modernismo", no livro Post-Modernismo no romance português contemporâneo. Fios de Ariadne. Máscaras de Proteu. Com efeito, se as reflexões de Arnaut (2002, p.17) acerca das várias linhas condutoras da teoria pósmodernista levam-na a crer que, na narrativa desta tendência literária, são "ostensivamente subversivas" características como a "mistura de gêneros", a "polifonia" e a "metaficção", é possível concluir que Nuno Júdice pratica uma poesia inserida nas perspectivas pós-modernistas, que, também de modo ostensivo, subverte o que se concebe como poema, misturando a polissemia própria do gênero poético à meditação e ao ensaio, a divisão em versos à estrutura prosaica; desconstruindo, enfim, a noção de poema como algo pronto, belo e acabado, inserindo-se na metapoesia de modo meditativo e crítico.

"A praia de Tourgeville" "desautomatiza" o leitor, que já não lê apenas um "poema" em suas noções canônicas, mas um poema que incorpora outros gêneros, mistura traços do ensaio, da própria poesia, e até da catalogação enciclopédica (na epígrafe). O mesmo acontece em outras criações contaminadas por procedimentos da narrativa ou por meditações, como "A procura da evidência” (JÚDICE, 1991, p.20), "Segundo poema sobre a morte" (JÚDICE, 1991, p.23) e "Destino e morte, espanto" (JÚDICE, 1991, p.50), o que se relaciona, mais uma vez, ao pós-modernismo literário, e 
sua tendência a causar "[...] a frustração das expectativas do leitor e a recusa em fornecer uma visão organizada e totalitária do mundo" (ARNAUT, 2002, p.43)6. "Pósmodernismo" ou não, o certo é que o poeta se insere entre as tendências mais relevantes da literatura de sua época.

Os textos do livro de 1972 têm títulos significativos como, por exemplo, "Matisse", "Os modos desconhecidos de ser", "O movimento da obsessão", "Regra de Composição", "Itinerário", "Stephane Mallarmé", "Os corredores do poema" e "Holderlin"; alguns, remetendo o leitor a outros artistas (como foi visto em "A praia de Tourgeville"), e revelando a "espaçosa genealogia" anunciada na primeira composição do livro; outros, relacionados à semântica do movimento - "itinerário" e "corredores do poema” entre eles -, enfim, "Os modos desconhecidos do ser” é, mais uma vez, uma especulação sobre o "ser" do poema, e note-se que são "desconhecidos" (não há apenas concepções já determinadas). A pergunta primeira colocada em "Apogeu da Gramática" - Como? - o poeta ainda tenta responder nesta, que é a nona composição do livro, conforme pode ser notado nos trechos transcritos:

A poesia é o teatro, diz-me uma voz interior. Representar-me em cada poema, montar-me um personagem, uma acção, um ambiente.

$[\ldots]$

Conheci a primeira das minhas derivações. Sentei-me a escrever, esperando por uma palavra, uma frase, uma citação que me permitissem avançar, sair do lugar estéril da memória, escrever. Comecei por receber uma revelação central, o núcleo do texto, a imagem que me forneceria o assunto. Depois, desenvolvendo verso a verso essa primeira intuição, pude esvaziá-la de toda a individualidade, fazê-la esquecer no conjunto ordenado do poema, dar-lhe emoção no ritmo próprio de cada estrofe.

(JUDICE, 1991, p.28)

O primeiro verso apresenta, de entrada, a subversão ontológica também própria da poética pós-modernista: “a poesia é teatro". Mais uma vez, questiona-se uma "noção", a do gênero poético, e rompem-se os limites de gêneros abertamente. Se 
autores modernos puderam praticar o hibridismo de forma menos ostensiva - inserindo, por exemplo, uma rubrica teatral no poema, misturando procedimentos poéticos na narrativa -, Nuno Júdice nem se preocupa em esconder a mélange des arts, sobretudo porque ela se apresenta no nível reflexivo da criação. Este, por sua vez, é exposto, como em uma vitrine, na segunda estrofe apresentada. Cumpre ressaltar que o discurso filosófico também contamina a composição, a começar pelo título, além de, por exemplo, na afirmação: “toda identidade é falsa” (JÚDICE, 1991, p.28)

Para Centeno, nas páginas de A Noção de Poema, "oscilamos", afirma, "entre o desejo (que se pretende lúcido) de uma Estética e a devastação real da criação poética" (1972, p.81). "Devastação" revelada em dezenas de versos: "Só, como se fosse a primeira vez, eu trabalho a página de um lado ao outro em branco" (1991, p.22), palavras do poema "O todo é pôr a maior relação possível"; "Veio-me ao espírito esta página. Ela desce, como um rio,/ para os largos estuários do amor” (1991, p.37), de "Itinerário"; "debruço-me atento/ para o movimento inútil das palavras sobre as palavras, das palavras/ sobre as frases" (1991, p.43), de "Os corredores do poema"; e em diversas outras composições. O vocábulo "poema(s)" aparece mais de quarenta vezes ao longo da coletânea, sem contar outras variantes que sinalizam a opção metadiscursiva, tais como "palavra", "poesia", "escrita", "verso", “canto", todas, em geral, suspendendo a crença de que se lê algo pronto e acabado, longe de seu processo construtivo. E o poeta não abandona essa prática, que ressurge em todos as suas coletâneas poéticas posteriores.

Um livro de Júdice de 1992, coletânea de "estudos e teorias críticas" é significativamente chamado O Processo Poético. Nele, de fato, o autor - poeta e crítico - atenta para as manipulações poéticas de diversos artistas, dos franceses do século XIX e XX (Baudelaire, Mallarmé, Valéry a Claudel) a poetas lusitanos como Antero de Quental, os modernistas, chegando até os autores da década de setenta (em que $A$ Noção de Poema fora publicada). No artigo "A poesia de setenta", o crítico reflete sobre os principais caminhos trilhados por poetas dessa década, em Portugal, ilustrando suas reflexões com poemas de Joaquim Miguel Fernandes Jorge, Joaquim Manuel Magalhães, António Franco Alexandre e Rui Diniz, este último, citado também pelas mesmas palavras que compõem a epígrafe de A Noção de Poema. 
A citação de Diniz vem a propósito de considerações de Júdice a respeito da ausência de teorias ou de uma poética organizada em torno dessas obras, concluindo o autor que isso é fato, "ainda que os poemas se procurem substituir ao raciocínio estético" (1992, p.165). E, antes de tal conclusão, o autor verificava que, nos poetas abordados, encontra-se

[...] a concepção do poeta enquanto personagem da linguagem - e não unicamente seu habitante. Se ele tem uma imagem, ele vai ao encontro da concepção do 'retrato em movimento' de que fala Herberto Helder, isto é, de uma concepção dinâmica do ser poético [...] (1992, p.164).

Essa é também a visão possibilitada pela obra A Noção de Poema: desvendando os "bastidores do poema", Nuno Júdice apresenta o poeta como personagem da linguagem - "a poesia é teatro" - e imprime em suas páginas o "retrato em movimento" do poema, de seu ato criativo, da própria poesia. Tudo isso em uma lírica movimentada e não econômica o uso das palavras.

Talvez o Júdice de Meditação Sobre Ruínas, obra de 1994 que mereceu o prêmio da APE, não se mostre assim tão intenso e agitado, bem como há vários poemas mais detidos, concisos, nessa obra. Segundo o próprio título aponta, o tom dos poemas é, de fato, mais meditativo, calmo. A agitação, o fluir livre dos versos, o movimento, enfim, diminui nessa obra que se faz serena, como se pedisse a postura do meditar. Porém, a obra ainda trata dos mesmos assuntos e das mesmas fixações do autor, as ruínas de outras obras ou artes, as ruínas do próprio poema e a reflexão. Sendo assim, sua recolha de estreia, ora analisada, não está tão longe desse seu grande livro da década de 90 .

Mostrando-se familiarizado com as experiências literárias mais importantes de sua época (neste caso, a década de setenta), mas de uma maneira muito própria, singular - o que sempre destaca um poeta entre seus pares - Nuno Júdice evidenciou, em $A$ Noção de Poema, que não lhe interessava somente o poema pronto: as inúmeras tendências, reflexões, questões, presentes na obra,relacionam-na à poética pósmodernista, apontando, sempre, para o movimento criativo. Desvendam-no. Interrogam e anulam qualquer "noção de poema" pré-concebida, revelando um poeta de grande 
alcance lírico, o que se confirmou em suas obras seguintes. Fica o leitor com a imagem, bastante impressiva, que encerra uma das criações do livro de 72: "Eis que está escrito. E mexe" (JUDICE, 1991, p.15)

\section{Referências}

ALVES, I. Nuno Júdice: Arte poética com melancolia. Boletim de pesquisa NELIC. Ilha de Santa Catarina, março de 2006, n. 08/09. http://www.cce.ufsc.br/ nelic/boletim8-9/idaferreiraalves.htm

ARNAUT, A. P. Post-modernismo no romance português contemporâneo. Fios de Ariadne. Máscaras de Proteu. Coimbra: Almedina, 2002.

CENTENO, Y. K. Nuno Júdice. A noção de poema. Colóquio Letras, Lisboa: Calouste Gulbenkian, n.09, p.80-81, setembro de 1972.

JUDICE, N. Meditação sobre ruínas. 2.ed. Lisboa: Quetzal, 1996.

O mecanismo romântico da fragmentação. Porto: Inova, 1975.

O movimento do mundo. Lisboa: Quetzal, 1996.

A noção de poema. Lisboa: Dom Quixote, 1972 (Col. Cadernos de Poesia). Obra poética (1972-1985). Lisboa: Quetzal, 1991.

O processo poético. Lisboa: Imprensa Nacional/Casa da Moeda, 1992.

PAZ, O. Los hijos del limo. México: Fondo de Cultura Económica, 2003.

1 Doutoranda do Programa de Pós-Graduação em Estudos Literários da UNESP Faculdade de Ciências e Letras - Araraquara - SP. Bolsa FAPESP. Email: chimenamsb@ hotmail.com

$2 \mathrm{O}$ poema foi dividido em partes, devido à sua longa extensão, para melhor fluir a análise aqui realizada. Do mesmo modo, está mantida sua apresentação gráfica no livro, pois esta também é importante.

3 Conferir seu célebre poema “O lutador”, publicado no livro José, de 1942.

4 O primeiro poema de $O$ Mecanismo Romântico da Fragmentação também apresenta, em determinado momento, essa relação entre o poeta, seu ato criador e a herança literária que o coloca entre a continuidade e a total ruptura. Os versos dizem: "[...] tenho/ alguns séculos de literatura, os olhos gastos,/ uma desmedida ambição de morrer no crepúsculo/ das gramáticas. Como // ignorá-las? [...]” (JÚDICE, 1975, p.13)

5 O interesse do poeta pela ideia de "movimento" não se dá só neste livro. Em 1996, publicou a obra $O$ Movimento do Mundo, cuja poética não se interessa pelo "movimento 
criativo" de modo tão obsessivo quanto na obra de 1972 (embora ela apareça), mas se baseia em outras conotações de "movimento". Já não é tão somente o movimento do poema, agora, é o do mundo.

6 A afirmação de Arnaut é, na verdade, um resumo das ideias de Willian Spanos, cuja concepção da tendência abrange todas as obras que "[...] desde tempos imemoriais ensombram a seriedade do cânone literário [...]" (ARNAUT, 2002, p.43). Com efeito, é sabido que, sobretudo na poesia, outras tendências como o surrealismo, por exemplo, tentou essa frustração de expectativa do leitor, fazendo-o interrogar e refletir sobre a arte. 